OPEN ACCESS

Edited by:

Alesia Coralie Ferguson,

University of Arkansas for Medical

Sciences, USA

Reviewed by:

Yearul Kabir,

University of Dhaka, Bangladesh Marie-Cecile Genevieve Chalbot, University of Alabama at Birmingham,

USA

${ }^{*}$ Correspondence:

Claire McAuley

cmcauley@intrinsik.com

Specialty section:

This article was submitted to

Environmental Health,

a section of the journal

Frontiers in Environmental Science

Received: 14 September 2016 Accepted: 14 November 2016 Published: 28 November 2016

Citation:

McAuley C, Dersch A, Kates LN,

Sowan DR, Koppe B and Ollson CA (2016) Assessment of Exposure to Chlorinated Organics through the

Ingestion of Moose Meat for a Canadian First Nation Community.

Front. Environ. Sci. 4:78.

doi: 10.3389/fenvs.2016.00078

\section{Assessment of Exposure to Chlorinated Organics through the Ingestion of Moose Meat for a Canadian First Nation Community}

\author{
Claire McAuley ${ }^{1 *}$, Ave Dersch ${ }^{2}$, Lisa N. Kates ${ }^{1}$, Darryel R. Sowan ${ }^{3}$, Bart Koppe ${ }^{1}$ and \\ Christopher A. Ollson ${ }^{4}$
}

${ }^{1}$ Intrinsik Corp., Calgary, AB, Canada, ${ }^{2}$ Moccasin Flower Consulting Inc., Slave Lake, AB, Canada, ${ }^{3}$ Swan River First Nation, Kinuso, AB, Canada, ${ }^{4}$ Ollson Environmental Health Management, Ancaster, ON, Canada

Moose is an important traditional food for members of the Swan River First Nation (SRFN), located in northern Alberta, Canada. As industrial development is encroaching on First Nations' traditional territories in northern Alberta, community members are growing increasingly concerned for the sustainability and safety of their traditional foods. The Alberta Special Waste Treatment Centre (ASWTC) is an industrial incineration facility located in the core of SRFN's traditional territory. An accidental release at the ASWTC in 1996 resulted in a significant discharge of polychlorinated biphenyls (PCBs) to the environment. In addition to this accident, the ongoing operation of the ASWTC is linked to routine low-level emissions of PCBs, polychlorinated dibenzo-p-dioxins and furans (PCDD/Fs). Since the 1996 release, levels of PCBs and PCDD/Fs have been measured in wild game tissues and the provincial government has issued consumption advisories. This study was undertaken to provide answers to the community regarding food safety and was designed to address concerns regarding PCB and PCDD/F concentrations in moose tissues. Samples of moose muscle $(n=15)$, liver $(n=13)$ and kidney $(n=14)$ were collected as part of regular food harvesting activities of the SRFN in the summer and fall of 2015 and generously shared by the SRFN hunters and harvesters to allow for their inclusion into the study. A risk assessment approach was used to evaluate the potential risks to human health using hazard quotients $(\mathrm{HQ})$. All HQs were below the benchmark level of 0.2 for a single pathway exposure. The results show that PCB and PCDD/F concentrations in moose tissues were low and comparable to those of meats available in Canadian supermarkets. Based on results from this study, community exposure to PCBs and PCDD/Fs from the consumption of moose tissue is low and consumption may continue at quantities documented in regional studies.

Keywords: human health risk assessment, traditional foods, moose, First Nations, PCB, PCDD, PCDF

\section{INTRODUCTION}

Traditional lifestyles for First Nations communities in northern Alberta, Canada have become increasingly difficult to sustain due to concerns over the decline in the quality, quantity, and biodiversity of many traditional resources as a result of industrial activities (Dersch, 2011). The implementation of unnecessary food consumption advisories can also have a devastating and 
long-lasting effect on remote and northern communities (McAuley and Knopper, 2011). Filling the dietary gap left by the removal or decline of traditional foods is often difficult in northern communities where alternative food options may not be available, are of poor quality or are very expensive (Van Oostdam et al., 2005). This is the case in the Swan River First Nation (SRFN) where members on fixed incomes do not have access to affordable and nutritious alternatives to traditional foods. Quality foods in grocery stores are expensive and not always accessible; therefore, affordable food options are often highly processed with low nutritive value (Dersch, 2011).

The SRFN is a Treaty 8 community located in northern Alberta, Canada (Figure 1), whose traditional and Treaty lands are increasingly being encroached upon for industrial uses and non-renewable resource development. Impacts to the traditional territories of SRFN include oil and gas activity, forestry, the Alberta Special Waste Treatment Centre (ASWTC), transmission and transportation corridors, agriculture and tourism.

The ASWTC is a hazardous waste processing facility that accepts hazardous, chemical and industrial waste from households, laboratories and industry. Treatment of organic wastes includes thermal treatment of persistent organic pollutants, polychlorinated biphenyls (PCBs) and polychlorinated dibenzo-p-dioxins and furans (PCDD/Fs). The facility is located on 320 acres, of which approximately 80 acres is fenced off (SENA, 2016). A 1996 accidental release of PCBs and PCDD/Fs from the ASWTC led to hair and blood monitoring of community members and resulted in the implementation of food advisories. The aftermath of the release caused widespread concern and fear about traditional food quality in the core of SRFN's traditional territory. This release, coupled with increased regional oil and gas development (and associated accidental releases) and forestry activity has caused traditional food quality to be a high priority issue among Swan River members.

The ASWTC is situated in the core traditional territory of SRFN and has caused deterioration in the local environment through the accidental release in 1996 and ongoing fugitive emissions of chlorinated organic compounds from the facility. Harvesting of traditional resources occurred extensively in the area prior to the development of the facility. Since the commencement of operations in 1989, and as the result of a subsequent upset event in 1996, many First Nations members have stopped traditional harvesting activities in this area (Dersch, 2011).

The awareness of releases from the ASWTC has focused the spotlight on the quality of traditional food in the area. According to the community Elders, the subsequent loss of confidence in traditional foods has led to a dramatic increase in heart disease, obesity and diabetes in the community of Swan River due to an increase in the consumption of "Western foods" (Dersch, 2011). Based on an awareness of the inextricable link between traditional food consumption and community well-being, First Nation studies of traditional food quality is a high priority in the community. Lesser Slave Lake Indian Regional Council (composed of SRFN and the other "Lakeshore Bands") has been investigating moose tissue quality since the ASWTC release in
1996 through various programs facilitated by industry and all levels of government (Dennis, 2008, 2014).

Consumption of all components of a harvested animal is important to First Nations. For this reason, and through continuation of traditional dietary practices, First Nation hunters and harvesters may have exposure to higher levels of contaminants than their non-Aboriginal counterparts. Organ meats (specifically the liver and kidney) typically have higher concentrations of chlorinated organic compounds than muscle tissue ("meat") (ATSDR, 1998). The consumption of moose muscle and organ tissue is central to the physical, social, and cultural wellbeing of SRFN members. The implementation of consumption advisories must be undertaken with caution, as SRFN members practice a subsistence lifestyle and having confidence in their food supply is of critical importance. Many elders do not digestively tolerate store bought meats and rely heavily on moose meat (Dersch, 2011).

The provincial government of Alberta has studied the concentrations of PCBs and PCDD/Fs in deer tissues, and placed a consumption advisory in the Swan Hills area (Alberta Health, 2013). While the consumption advisory was derived using data from deer tissue, it applies to all "game meat." Animals with smaller home ranges, such as deer and grouse, which are in the direct depositional area of the ASWTC, would be more directly affected by fugitive and operational emissions from the facility. Animals with larger home ranges, such as moose, would likely spend smaller portions of their lifespan in the vicinity of the facility and thereby would be influenced to a lesser degree. The current advisory recommends a consumption limit of 150 grams per day for wild game harvested within a $15 \mathrm{~km}$ radius of the ASWTC. This advisory has changed considerably from the initial advisory issued shortly after the release in 1996, which was a "zero consumption" advisory for animals caught within $30 \mathrm{~km}$ of the facility.

Despite the revised consumption advisory by Alberta Health in 2013, many community members remain concerned about the quality of moose meat harvested in their traditional lands, leading to altered hunting patterns and the burden of needing to harvest moose further away from the facility. In addition to the 1996 release, the ongoing operation of the ASWTC is linked to routine low-level emissions of contaminants. An assessment of snow cores in 2012 by the SRFN identified contamination of both fugitive PCB emissions from the ASWTC on-site tank farm and PCDD/F emissions resulting from the facility incinerator at distances up to $18 \mathrm{~km}$ from the site, but with decreasing concentrations at increasing distance (SRFN, 2012). The continuous release of $\mathrm{PCBs}$ and $\mathrm{PCDD} / \mathrm{Fs}$ is of concern to local Nations; however, the magnitude is such that levels may not be detectable in local moose populations. Previous studies on PCB and PCDD/F levels in moose tissue from the SRFN area have shown that chlorinated organic concentrations in moose tissue were below community-specific tolerable daily intake levels (Dennis, 2008, 2014). The aim of this harvest and tissue quality study was to obtain a large enough sample size to adequately characterize the concentrations of chlorinated organic compounds in locally harvested moose in order to provide members of the SRFN confidence in their 


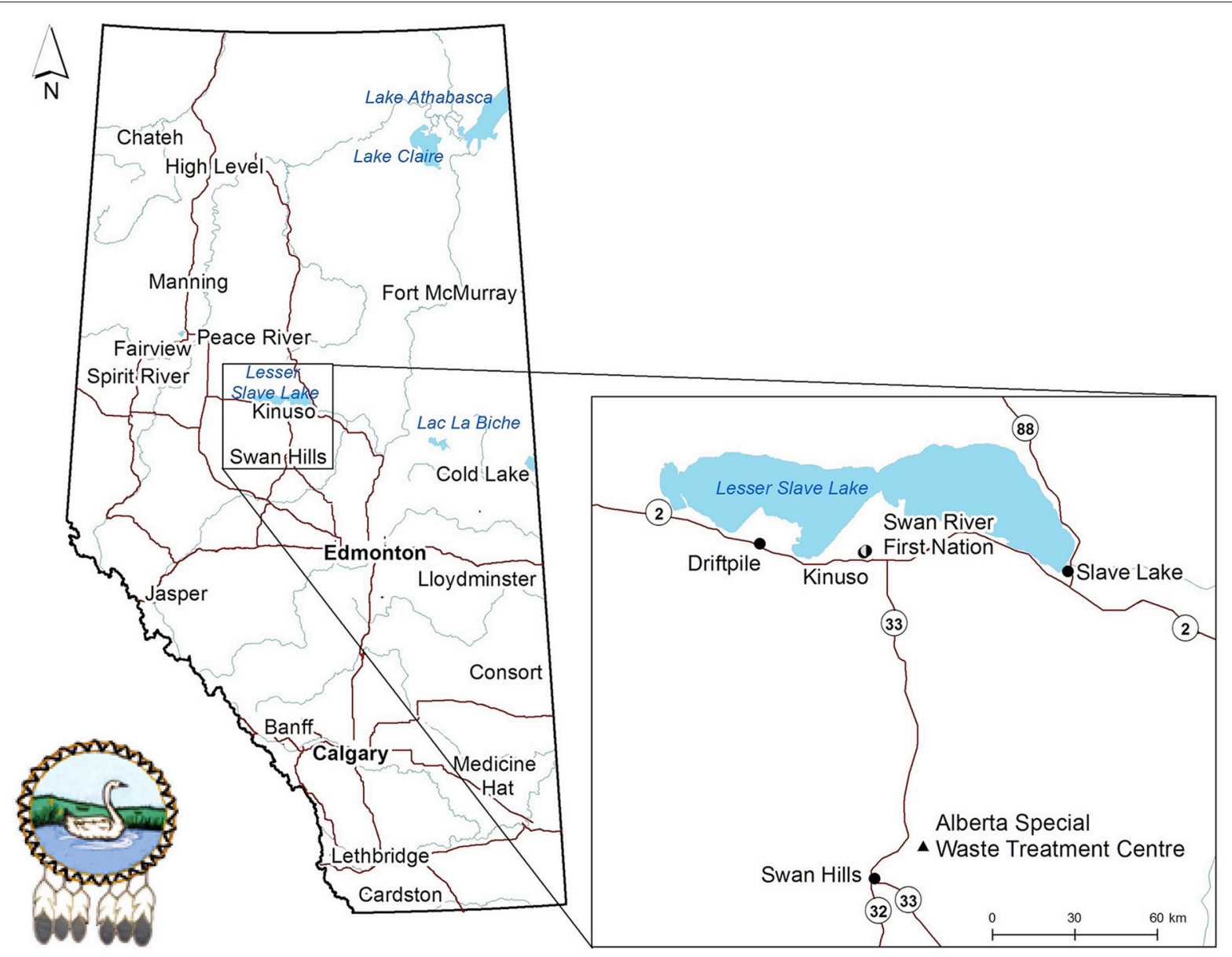

FIGURE 1 | Map of Alberta showing the study location.

traditional food supply and to put the consumption advisory into perspective.

\section{MATERIALS AND METHODS \\ Sample Collection}

The sampling undertaken for this program was communitybased and was coordinated by the SRFN. A workshop was held in the community to discuss the program, to distribute 15 sample kits and to review the sampling protocols and study objectives. Sampling objectives were to collect tissues from moose (Alces alces) including muscle, liver, and kidney. Specific emphasis was placed on sample collection and sample dissection, stressing both sample integrity and reviewing potential sources of contamination.

Moose tissue samples were collected by community harvesters trained in sample collection, documentation and storage as part of their regular hunting activities over the summer and fall of 2015. The samples were collected as part of the regular food harvesting activities of the SRFN members in their traditional territories. Samples were collected opportunistically and then generously shared and portioned to allow for their inclusion in this study. The specific sample collection and harvesting locations were based on the traditional knowledge of the SRFN hunters. Nine samples were collected within a radius of approximately $15 \mathrm{~km}$ from the town of Kinuso, five samples were collected between Kinuso and the town of Swan Hills, with the closest sample to the ASWTC collected approximately $15 \mathrm{~km}$ northeast from the plant. One additional sample was collected near the town of Spirit River, located approximately $250 \mathrm{~km}$ northwest of the ASWTC (Figure 1). In order to protect the privacy of the community hunters, specific harvesting locations are not provided herein. Although harvesting locations were documented it is understood that a limitation of the study is the precise knowledge of the previous grazing locations of the animals included in the study.

Community harvesters were provided with gloves, knives, Ziploc ${ }^{\circledR}$ bags, coolers, cold packs, and labels. Each sample was prepared using a new set of gloves and new knife blade. Approximately one pound of each tissue type was requested. Muscle tissue was collected from the back left leg with no skin, hair or bone. Liver tissue was dissected from the middle section of the organ, while one entire kidney was requested. Samples were transported to the community 
freezer using coolers with cold packs. No field duplicates were submitted.

Samples were labeled and held in the community freezer at $-20^{\circ} \mathrm{C}$ prior to shipment to an analytical laboratory in Sydney, BC (AXYS Analytical Services, Inc.; AXYS). Once received at AXYS, all tissue samples were homogenized. One lab-created duplicate for each tissue type was analyzed for quality assurance and quality control purposes.

The study set a target of 15 samples each of moose muscle, liver and kidney to be collected. Final sample numbers varied slightly upon completion of the moose harvest and the total numbers of samples included were 15 muscle, 13 liver, and 14 kidney.

\section{Analytical Methods and Detection Levels}

PCBs, PCDDs, and PCDFs were quantified by AXYS using gas chromatography (GC) coupled with a high resolution mass spectrometer (HRMS), following United States Environmental Protection Agency (US EPA) methods 1668A and 1613B. All 209 PCB congeners and 17 PCDD/F congeners were quantified. The detection limit for PCBs was $0.1 \mathrm{pg} / \mathrm{g}$, except for the dichlorinated PCBs, which had a detection limit of $0.2 \mathrm{pg} / \mathrm{g}$. The detection limit for all the PCDD/Fs was $0.05 \mathrm{pg} / \mathrm{g}$. Detection limits were based on a $10 \mathrm{~g}$ sample size.

\section{Calculation of Toxic Equivalency}

In order to complete the assessment of the PCDD/F and dioxinlike $\mathrm{PCB}$, measured concentrations were converted to toxic equivalent quotients (TEQ). These compounds were grouped as they have the same mechanism of action and the most potential to cause adverse health effects. The toxic potency of these compounds depends on the position and number of bonded chlorine atoms and was expressed relative to the most toxic congener (i.e., 2,3,7,8-tetrachlorodibenzodioxin, TCDD) as a TEQ through the use of toxicity equivalency factors (TEF). The TEF approach allowed the toxic potency of PCB, PCDD, and PCDF to be estimated based on their relative potency to 2,3,7,8-TCDD.

The calculation of TEQ was performed using TEF published by the World Health Organization (Van den Berg et al., 2006) and adopted by Health Canada (2012). For those chemicals that were below the laboratory detection limit (non-detect or ND), a value equal to the detection limit (DL) was used in the TEQ calculations (i.e., $\mathrm{ND}=\mathrm{DL}$ ).

Substitution using the detection limit was used in order to provide a conservative estimate of exposure and to avoid underestimating risk. This substitution method is common practice in risk assessment, and may tend to over-estimate predicted exposure (BC MOE, 1995; US EPA, 1996). Different methods of dealing with non-detects include substituting the values for half of the detection limit, which would result in a less conservative value, or substituting the non-detected values with zero, which would also result in a less conservative value. Alberta Health used the latter method in the wild game and fish monitoring report that formed the basis of the current Swan Hills consumption advisory (Alberta Health, 2013).

\section{Consumption Rates}

Consumption data were collected from the community as part of the moose tissue quality study. In order to respect the confidential nature of community specific consumption data, these data were not used in this risk assessment, rather consumption rates of moose muscle, liver and kidney were obtained from the 2016 First Nations Food, Nutrition and Environment Study (FNFNES) for Alberta (Chan et al., 2016). Data from the Boreal Plains ecozone, where the SRFN is located, were used in this study for the calculation of hazard quotients. Consumption details for toddlers were not collected in the FNFNES study. In order to identify the consumption patterns for toddlers, a ratio based on the Health Canada wild game consumption values for Aboriginal toddlers vs. adults $(85 \mathrm{~g} / 270 \mathrm{~g}=0.315)$ was applied to the adult consumption rates (Health Canada, 2012). Consumption rates used in this assessment are provided in Table 1.

\section{Human Health Risk Assessment}

A human health risk assessment (HHRA) was conducted following a traditional risk assessment paradigm developed by various regulatory agencies, such as Health Canada (Health Canada, 1995, 2012) and the US EPA (US EPA, 1991). The traditional risk assessment paradigm included a three pronged approach: exposure assessment, toxicity assessment and risk characterization.

\section{Exposure Assessment}

The exposure assessment was limited to the ingestion of moose tissue by members of the SRFN. The exposure assessment predicted the rate of exposure (i.e., the quantity and rate at which a chemical of potential concern is received) of humans to chlorinated organics via the ingestion pathway alone. Human exposure was calculated using Chronic Daily Intake (CDI) values (Equation 1).

$$
C D I=\frac{I R \times E P C}{\text { Bodyweight }}
$$

Where:

$\mathrm{CDI}=$ chronic daily intake (mg chemical/kg bw-day)

$\mathrm{IR}=$ ingestion rate $(\mathrm{kg} /$ day $)$

$\mathrm{EPC}=$ exposure point concentration $(\mathrm{mg} / \mathrm{kg})$

CDI values were calculated for both the toddler and adult receptor. Toddlers were assumed to have a body weight of 16.5 $\mathrm{kg}$, while $70.7 \mathrm{~kg}$ was used for adults (Health Canada, 2012). The ingestion rates of moose muscle, liver and kidney for the toddler and adult receptors are provided in Table $\mathbf{1}$.

TABLE 1 | Mean (high) consumption rates of moose tissue used in the risk assessment ( $g /$ day).

\begin{tabular}{lcc}
\hline Moose Tissue & Toddler (g/day) & Adult $(\mathbf{g} /$ day) \\
\hline Muscle & $6.5(29.8)$ & $20.5(94.5)$ \\
Liver & $1.1(7.2)$ & $3.4(23)$ \\
Kidney & $1.0(5.4)$ & $3.3(17.3)$
\end{tabular}


The exposure point concentration (EPC) was used to estimate a reasonable upper limit value for the average chemical concentration in the tissue, determined for each exposure unit (US EPA, 1989). Statistical analysis was completed to determine the point estimate values representative of reasonable maximum exposure. The US EPA software program ProUCL (ver.5.0.00) was used to estimate EPC-values (US EPA, 2013). The US EPA (2002) recommends using upper confidence limits (UCLs) for assessing EPCs. ProUCL 5.0.00 provides 15 upper confidence limit computational methods and is considered appropriate for both small and large datasets, as well as datasets with a large number of non-detects (US EPA, 2013).

\section{Toxicity Assessment}

The objective of the toxicity assessment was to identify the potential adverse health effects associated with each chemical of potential concern (COPC) as a consequence of chronic exposure. Toxicity reference values (TRVs) generated by federal health agencies, were used to evaluate an acceptable level of exposure. TRV s are defined as the chronic daily dose of a COPC at or below which adverse effects are not expected to occur. The TRVs used in the HHRA were those endorsed by Health Canada (2010) and are provided in Table 2 .

\section{Risk Characterization}

Risk characterization was the final step in the risk assessment and involved quantifying and estimating potential health risks. The risk characterization step combined the results from the exposure assessment and the information from the toxicity assessment to estimate the potential risks to human health from the COPC evaluated. Risk characterization was essentially a comparison of the predicted human intake of a COPC to the TRV for that COPC. In this assessment, chronic health risks were assessed for non-carcinogenic COPC via the ingestion pathway of exposure.

The concept of hazard quotients was used to determine non-carcinogenic risk. The hazard quotient (HQ) represents the relationship (ratio) between the magnitude of exposure to the contaminant and a TRV. As only the oral exposure pathway was considered for the purposes of this assessment, an HQ of 0.2 was used as a benchmark to assess risk level for non-carcinogenic exposures. This allowed for exposure to organochlorines through other routes (air, water, dermal contact, and commercially available foods). An HQ of 0.2 assumed an exposure of $20 \%$ of the allowable level to come from the traditional foods and $80 \%$ to come from other sources (both food for ingestion and exposures through other routes). This was a conservative approach, following Health Canada guidelines (Health Canada, 2012), as exposure to PCBs and PCDD/Fs from

TABLE 2 | Health Canada toxicity reference values for chlorinated organics used in the assessment (Health Canada, 2010).

\begin{tabular}{ll}
\hline Chemical & TRV \\
\hline Total PCB & $0.13 \mu \mathrm{g} / \mathrm{kg}$ bw/day \\
Dioxin-like PCB & Evaluated as PCDD/F \\
PCDD/F & $2.3 \mathrm{pg} / \mathrm{kg} \mathrm{bw} /$ day
\end{tabular}

other routes is extremely low. If the HQ ratio was greater than the benchmark of 0.2 , then there may be potential for adverse health effects and further assessment may be required. An HQ of less than the regulated benchmark (0.2) indicated that the intake of the COPC through the consumption of traditional foods did not exceed the tolerable daily intake and no adverse health effects were expected.

For risk characterization of non-carcinogenic COPC, HQs were calculated for each chemical by deriving CDI values (Equation 1) of exposed receptors and weighing these against the respective TRVs. Equation 2 was used to calculate the hazard quotient.

$$
H Q=\frac{C D I}{T R V}
$$

Where:

$\mathrm{HQ}=$ hazard quotient (unit less)

$\mathrm{CDI}=$ chronic daily intake (mg COPC/kg body weight-day) or dose

$\mathrm{TRV}=$ toxicity reference value (mg COPC/kg body weight-day)

\section{Benchmark Consumption Quantities}

In order to contextualize the risk, benchmark consumption quantities were calculated to determine the number of meals per year that are safe to consume. In assuming a single pathway exposure, benchmark consumption quantities were calculated with an $\mathrm{HQ}=0.2$ following Equation 3, 4. Portion size was obtained from the Alberta FNFNES study (Chan et al., 2016) as the mean portion size from a 24 -h recall study, averaged across age groups and gender and amortized for lifetime exposure. Toddler portion sizes were calculated as a 0.315 ratio to the amortized adult portion sizes.

$$
\begin{aligned}
\text { Max consumption } & =\frac{(0.2 \times T R V) \times \text { body weight }(\mathrm{kg})}{E P C} \\
\text { Meals } / \text { year } & =\frac{\text { Max consumption }}{\text { Portion Size }} \times 365
\end{aligned}
$$

\section{RESULTS}

Moose muscle, liver, and kidney samples were analyzed for a suite of chlorinated organics, including PCB and PCDD/F. Although the goal was to collect 15 moose samples for each of muscle, liver and kidney, the final numbers upon completion of the harvest were 15 unique muscle, 13 unique liver, and 14 unique kidney samples.

\section{Analytical Results}

Summary statistics were calculated for each of the muscle tissue and organ samples. These summary statistics included the number of values below the detection limit (non-detects), the range (minimum, maximum) and mean. Summary statistics are shown in Table 3 for PCBs and Table 4 for PCDD/Fs.

In muscle tissue, the range of total PCBs was $27 \mathrm{pg} / \mathrm{g}$ ww to $100 \mathrm{pg} / \mathrm{g} \mathrm{ww}$, with a mean concentration of $44 \mathrm{pg} / \mathrm{g}$ ww. 


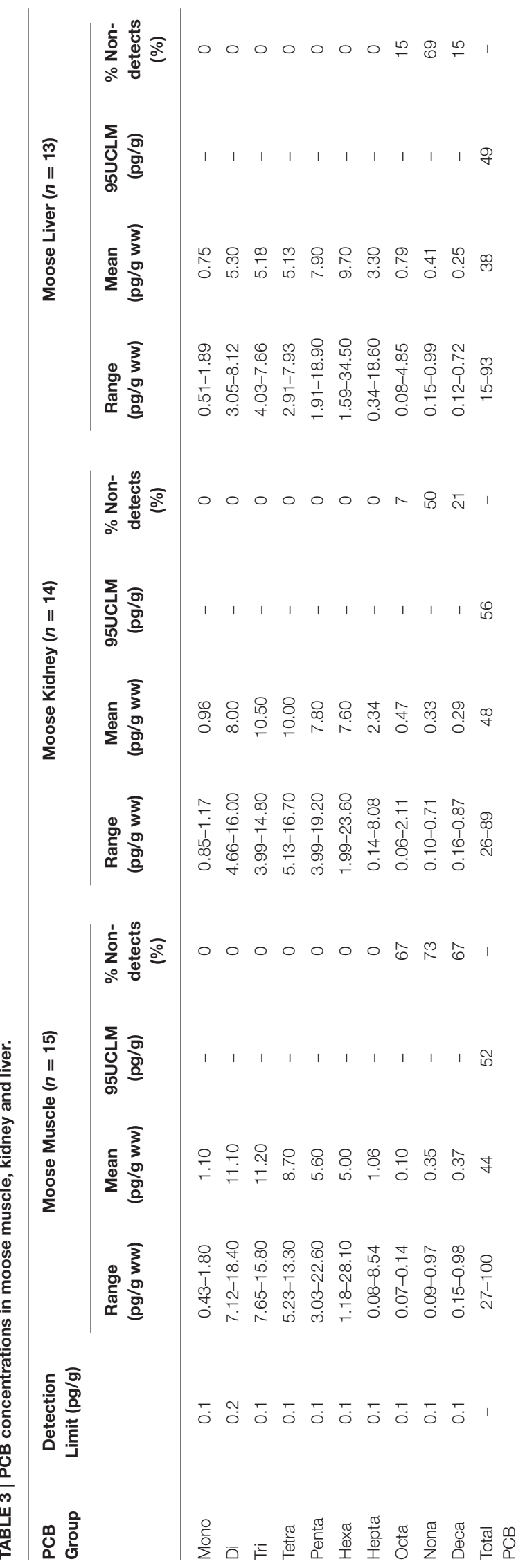

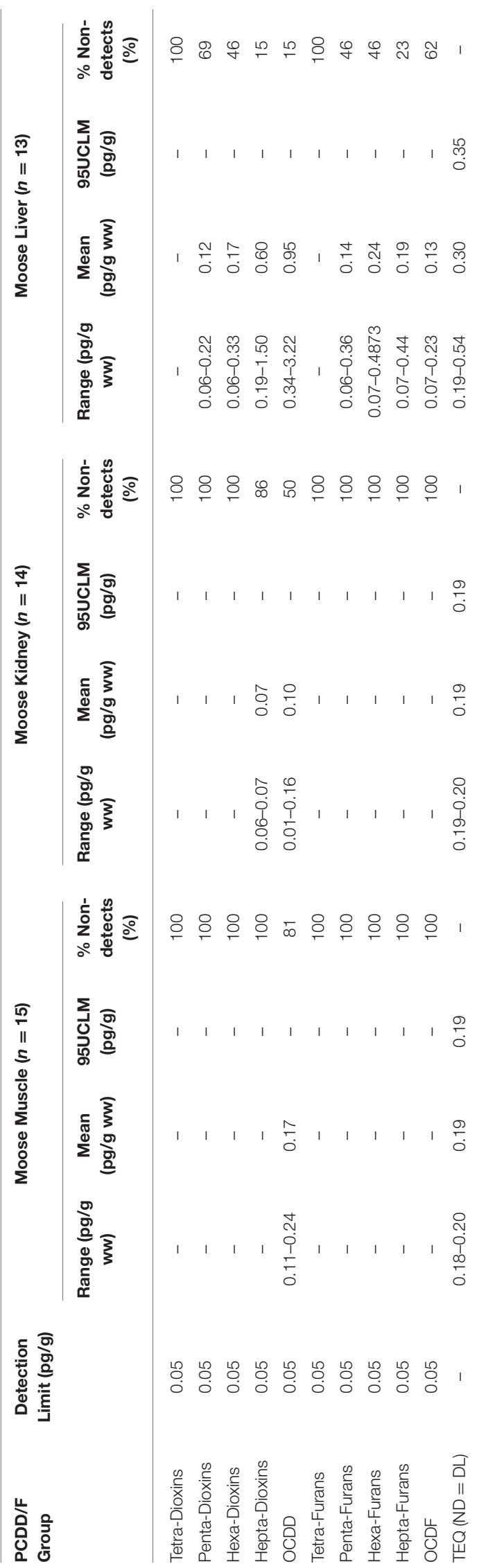


All of the lesser chlorinated PCBs were present in all samples, however many of the more heavily chlorinated PCBs, the oct-, nona-, and deca-chlorinated biphenyls, were below the detection limit in most of the samples. For PCDD/Fs in the muscle tissue, the only compound that was above the detection limit was octachlorodibenzodioxin (OCDD), which was detected in only three of 15 samples. The range of OCDD in muscle was $0.11-0.24$ $\mathrm{pg} / \mathrm{g}$ ww, with a mean of $0.17 \mathrm{pg} / \mathrm{g}$ ww. Using the substitution method, the mean TEQ in the muscle tissue was $0.19 \mathrm{pg} / \mathrm{g}$ ww.

PCB concentrations in the liver and kidney samples had similar trends as in the muscle samples. All PCBs were above the detection limit, except for the oct-, nona-, and deca-chlorinated biphenyls, which were non-detects in many of the samples. Mean total PCB concentrations in the liver and kidney samples were 38 and $48 \mathrm{pg} / \mathrm{g} w \mathrm{w}$, respectively, with ranges of 15-93 and 26-89 $\mathrm{pg} / \mathrm{g} \mathrm{ww}$, respectively.

In the kidney samples, PCDD/Fs were predominantly below the detection limits. The only PCDD/Fs detected were the heptachlorinated dibenzodioxins and OCDD, present in only 20 and $50 \%$ of the samples, respectively. The mean TEQ in the kidney samples was $0.19 \mathrm{pg} / \mathrm{g}$ ww. The liver samples had higher levels of PCDD/Fs than the other tissue types with a mean TEQ of $0.30 \mathrm{pg} / \mathrm{g}$ ww. The only non-detected PCDD/Fs in the liver tissues were the tetra-chlorinated dibenzodioxins and the tetrachlorinated dibenzofurans. All other PCDD/Fs were detected in at least four samples.

When duplicate tissue samples were present, the sample labeled as "duplicate" from the lab was excluded from the summary statistic calculations. The lab-created duplicates were used for laboratory quality control and to calculate relative percent difference (RPD) between the two measurements. The RPD for total PCB concentrations in the muscle duplicates was $0 \%$, with liver and kidney showing more variability at 16 and $11 \%$, respectively. Total TEQ values were predominantly below the detection limits, rendering the RPD calculations irrelevant as the detection limit was substituted for non-detected samples.

Following the recommendation from the ProUCL software, the EPC selected was the 95th percentile upper confidence level of the mean (95UCLM). The 95UCLM was used to calculate hazard quotients for total PCB and TEQ (Tables 3, 4) for those groups only. For calculation of the 95UCLM, non-detected values were assigned a value equal to the detection limit. This conservative approach is appropriate when data are to be used in consumption risk assessment.

\section{Examination of Congener Profiles}

The aim of this study was to assess the quality of the moose tissue, not to determine the source of PCB and PCDD/F. However, review of the congener profiles from the $\mathrm{PCDD}$ analyses provided insight as to the source of the emissions. The PCDD/F profiles from the moose tissue samples are provided in Table 4.

The results of the $\mathrm{PCDD} / \mathrm{F}$ distribution showed that most of the detectable total $\mathrm{PCDD} / \mathrm{F}$ in the moose tissue was OCDD, which has been linked to the combustion of forest fires (Meyer et al., 2007). The second most abundant congener in all tissue types were the hepta-chlorinated dibenzodioxins (HpCDD). HpCDDs have been linked to emissions from diesel trucks, unleaded gasoline vehicle emissions, and industrial wood combustors (Cleverly et al., 1997). Levels of penta- and hexachlorinated dibenzodioxins, which have been linked to PCB pyrolysis (Hutzinger et al., 1985), were not detected in the muscle and kidney tissues. The congener profile of PCDDs in the liver tissue showed OCDD and HpCDDs as well as pentaand hexa-dioxins. The penta- and hexa-dioxins were present in the liver tissue with abundance levels at 2 and 5\%, respectively. This suggests that both forest fires and PCB combustion may contribute to total PCDD levels in the tissue. The abundance of $\mathrm{OCDD}$ as the major contributor in all tissue types indicates that forest fires may be an important source of PCDDs in the area.

\section{Calculation of Human Exposures}

Chronic daily intake values for total PCBs were calculated for adults using the mean consumption rate as well as the high consumption rate provided in the FNFNES for Alberta (Chan et al., 2016) and summarized in Table 1. The CDI values for PCBs and TEQ are presented in Table 5. The HQ values for total PCBs and total TEQ were calculated using Equation 2 and the CDI values shown in Table 5. The HQ values for total PCBs and total TEQ are presented in Table 6. All of the HQ values for all tissue types and all consumers were below 0.2 . The high consumers had slightly higher HQ values due to the larger consumption rate, however they were often within the same order of magnitude as the average consumer. HQ values for PCBs in toddlers ranged from 2.72E-05 to 7.28E-04, with the organ tissues having the lowest HQ values and muscle having the highest. Similar patterns were seen for PCBs in the adult consumer, with HQ values ranging from $1.80 \mathrm{E}-05$ to $5.4 \mathrm{E}-04$. Total TEQ HQ values followed similar patterns as the PCBs, with lower HQ values in the organ meats than the muscle tissue for both the toddler and adult. TEQ HQ values for the toddler ranged from $5.34 \mathrm{E}-03$ to $1.50 \mathrm{E}-01$ and for the adult ranged from $3.96 \mathrm{E}-$ 03 to $1.11 \mathrm{E}-01$. Even though the organ tissues had higher levels of COPC present, the much lower consumption rate for organ tissues resulted in lower HQ values.

\section{Calculation of Benchmark Consumption Quantities}

Using an HQ of 0.2 as a benchmark for both adults and toddlers, annual consumption quantities were calculated for the moose muscle only. The benchmark consumption quantities were calculated for TEQ only and did not take into consideration other contaminants that may be present, such as metals. For example, because cadmium concentrations tend to be elevated in the liver and kidneys of large game, cadmium has been shown to be a limiting factor for the consumption of moose liver and kidney (Chan et al., 2016). Therefore, benchmark consumption quantities based on TEQs were not calculated for liver and kidney, as it would not reflect the true benchmark consumption quantities associated with eating organ meat. The muscle consumption quantities were calculated using the 95UCLM tissue concentrations. Based on a muscle serving size of $47 \mathrm{~g}$, toddlers can consume up to 307 meals of moose muscle per year. For adults, consumption of up to 414 meals per year of muscle was calculated based on a serving size of $150 \mathrm{~g}$. 
TABLE 5 | CDI values for PCB and TEQ levels in moose tissue.

\begin{tabular}{|c|c|c|c|c|c|c|c|}
\hline \multirow[t]{2}{*}{ COPC } & \multirow[t]{2}{*}{ Consumption Rate } & \multicolumn{3}{|c|}{ Toddler (pg/kg bw/day) } & \multicolumn{3}{|c|}{ Adult (pg/kg bw/day) } \\
\hline & & Muscle & Kidney & Liver & Muscle & Kidney & Liver \\
\hline \multirow[t]{2}{*}{ PCB } & Average & $2.05 E+01$ & $3.54 \mathrm{E}+00$ & $3.15 \mathrm{E}+00$ & $1.52 \mathrm{E}+01$ & $2.62 \mathrm{E}+00$ & $2.34 \mathrm{E}+00$ \\
\hline & High & $9.46 \mathrm{E}+01$ & $1.85 \mathrm{E}+01$ & 2.13E+01 & 7.02E+01 & $1.37 \mathrm{E}+01$ & $1.58 \mathrm{E}+01$ \\
\hline \multirow[t]{2}{*}{ TEQ } & Average & 7.47E-02 & $1.23 \mathrm{E}-02$ & $2.25 \mathrm{E}-02$ & 5.54E-02 & $9.10 \mathrm{E}-03$ & 1.67E-02 \\
\hline & High & $3.44 \mathrm{E}-01$ & 6.44E-02 & $1.52 \mathrm{E}-01$ & $2.55 \mathrm{E}-01$ & 4.77E-02 & $1.13 E-01$ \\
\hline
\end{tabular}

TABLE 6 | $\mathrm{HQ}$ values for PCB and TEQ in moose tissue.

\begin{tabular}{|c|c|c|c|c|c|c|c|}
\hline \multirow[t]{2}{*}{ COPC } & \multirow[t]{2}{*}{ Consumption Rate } & \multicolumn{3}{|c|}{ Toddler } & \multicolumn{3}{|c|}{ Adult } \\
\hline & & Muscle & Kidney & Liver & Muscle & Kidney & Liver \\
\hline \multirow[t]{2}{*}{ PCB } & Average & $1.58 \mathrm{E}-04$ & $2.72 \mathrm{E}-05$ & $2.42 \mathrm{E}-04$ & 1.17E-04 & 2.02E-05 & $1.80 \mathrm{E}-05$ \\
\hline & High & $7.28 \mathrm{E}-04$ & $1.43 \mathrm{E}-04$ & $1.64 \mathrm{E}-04$ & $5.40 \mathrm{E}-04$ & 1.06E-04 & 1.22E-04 \\
\hline \multirow[t]{2}{*}{ TEQ } & Average & 3.25E-02 & 5.34E-03 & 9.79E-03 & $2.41 E-02$ & 3.96E-03 & 7.26E-03 \\
\hline & High & $1.50 \mathrm{E}-01$ & 2.80E-02 & 6.62E-02 & $1.11 \mathrm{E}-01$ & 2.07E-02 & 4.91E-02 \\
\hline
\end{tabular}

\section{DISCUSSION}

The analysis of PCBs and PCDD/Fs in moose tissue from the Swan Hills area was carried out in order to determine whether or not the muscle and organs are safe to eat. Chemical concentrations of PCBs and PCDD/Fs in moose tissues were incorporated in two ways: calculation of an HQ to assess exposure risk through community specific consumption rates and through the calculation of benchmark consumption quantities. The calculated HQ values for all tissue samples did not exceed an HQ limit of 0.2 for a single exposure pathway, which indicated limited potential for harmful health effects to humans from these contaminants.

Benchmark consumption quantities for moose tissues were calculated using TEQ values only. In order to limit exposure to an HQ of 0.2 , the maximum number of meals an adult or toddler may consume far exceeded the reported consumption rates for First Nations communities in the area (Chan et al., 2016). For example, an adult would be able to safely consume $62 \mathrm{~kg}$ of moose muscle per year. The reported average annual consumption of moose muscle by First Nations in the Boreal Plains ecozone was $34 \mathrm{~kg}$ per year (Chan et al., 2016).

\section{Inclusion of Background TEQ Exposure}

Human exposure to $\mathrm{PCBs}$ and $\mathrm{PCDD} / \mathrm{Fs}$ is primarily from food consumption. In order to include $\mathrm{PCB}$ and $\mathrm{PCDD} / \mathrm{F}$ background exposure from other foods, overall hazard quotients were calculated using Equation 5.

$H Q=\frac{\text { (Average daily background }+C D I \text { from moose consumption) }}{T R V}$

HQ values were interpreted using the notion that an HQ $>1.0$ may signify potential health risks. The average daily
TABLE 7 | HQ values for TEQ in moose tissue including background exposure for the adult receptor (ND = DL).

\begin{tabular}{llll}
\hline Receptor & Muscle & Kidney & Liver \\
\hline Adult mean consumer & $2.94 \mathrm{E}-01$ & $2.74 \mathrm{E}-01$ & $2.77 \mathrm{E}-01$ \\
Adult high consumer & $3.81 \mathrm{E}-01$ & $2.90 \mathrm{E}-01$ & $3.19 \mathrm{E}-01$ \\
\hline
\end{tabular}

background value was obtained from Health Canada (2005) and the consumption rate was determined from the results of the FNFNES Alberta results (Chan et al., 2016). Comparing the HQ value against 1.0 assumed that all $\mathrm{PCB}$ and $\mathrm{PCDD} / \mathrm{F}$ exposure came from the dietary pathway. Using data from 1998 to 1999 , Health Canada (2005) calculated an average dietary intake for adults of $0.62 \mathrm{pg}$ TEQ $/ \mathrm{kg}$ bw/day.

By combining the average daily background $(0.62 \mathrm{pg} / \mathrm{kg}$ bw/day) with the CDI values and using a Health Canada TRV value of $2.3 \mathrm{pg} / \mathrm{g}$ TEQ, HQ values including background exposure were calculated and are presented in Table 7. Hazard quotients including background exposure for the toddler receptor were not calculated as there was insufficient information regarding background TEQ exposure for toddlers.

All of the HQ values for the adult receptors were below the benchmark value of 1.0 (Table 7). The HQ values including background exposure range from a low of 0.27 for kidney tissue for the mean consumer to a high of 0.38 for muscle tissue for the high consumer. With background exposure taken into account, even the scenario of the high consumer had a HQ value below 1.0. This indicates that when the total diet was taken into account, PCB and PCDD/F TEQ exposure was not anticipated to result in negative health effects for any adult receptor. 


\section{Comparisons to National Canadian Data}

In order to contextualize the TEQ levels found in the 2015 moose samples from this study, TEQ levels were compared with beef products and organ meats from the Canadian Total Diet Study (Health Canada, 2016) as well as moose muscle and organ samples from the FNFNES. FNFNES results were compiled from Ontario (Chan et al., 2014), Manitoba (Chan et al., 2012), and British Columbia (Chan et al., 2011). The Alberta FNFNES study (Chan et al., 2016) did not report concentrations of PCBs or PCDD/Fs. The TEQ results from the FNFNES studies were for $\mathrm{PCDD} /$ Fs only and did not include dioxin-like PCBs. The sample sizes from the FNFNES studies were small, ranging from one to nine muscle and liver samples, and no kidney data were reported.

Overall, the SRFN moose muscle samples were within the range of TEQ values from beef products in the Canadian total diet study, however the organ tissues from the SRFN were at the higher end of the range for organ meats. Average TEQ levels for moose muscle $(\mathrm{ND}=\mathrm{DL}$ ) were in the same range as beef steak, while liver and kidney samples were on the higher end of the range of "organ meats." Unfortunately, the diet study did not provide additional details regarding what type of animal the organ tissue came from. The diet study was somewhat dated and also did not provide sample numbers or any summary statistics, therefore the value in comparing SRFN data to the diet study is limited.

Comparison between the SRFN data and the FNFNES studies showed that TEQ levels in the SRFN muscle tissue were above those from BC and Manitoba, but well below TEQ levels from Ontario moose muscle samples. There were no liver data reported for Manitoba, and SRFN TEQ levels were below those from Ontario and higher than liver data reported for BC. PCB and $\mathrm{PCDD} / \mathrm{F}$ concentrations were not measured in the Alberta FNFNES study. All three FNFNES studies completed to date have low sample numbers for moose tissues $(n=1-9)$, which limits the data interpretation. Information on where the animals were harvested for the FNFNES studies was not provided, which also limited the value in comparing data sets.

\section{Comparison to Existing Alberta Health Consumption Advisory}

After the upset event in 1996, Alberta Health issued a public health notice advising against eating wild game caught from within a $30 \mathrm{~km}$ radius of the ASWTC. In 1997, further tests determined that eating wild game from the Swan Hills area posed no immediate threat to human health, thereby changing the "zero consumption" warning to a consumption limit of 370 grams per month. As of May 2013, the consumption advisories for game meat are: 150 grams per day of wild game meats collected within a $15 \mathrm{~km}$ radius of the ASWTC; consumption of organ meat (liver, kidney) or using fat from wild game harvested within a $15 \mathrm{~km}$ radius of the ASWTC is not recommended; and pregnant or breast-feeding women and young children should avoid eating wild game harvested within a $15 \mathrm{~km}$ radius of the ASWTC (Alberta Health, 2013).

The 2013 consumption limit was based on a study of deer tissue samples collected in the Swan Hills area from 1999 to 2010 (Alberta Health, 2013). Animals were harvested at a range of distances from the ASWTC, from the facility boundary up to $30 \mathrm{~km}$ away from the facility. Alberta Health used $t$ tests to compare tissue sample concentrations against deer collected from an unspecified reference area. Despite statistically significant differences with the reference site, calculated daily exposures, using a consumption rate of $190 \mathrm{~g}$ muscle and $2 \mathrm{~g}$ per liver per day, were still within the Health Canada tolerable daily intake amount. Hazard quotients calculated from the 2010 data for total TEQ in deer muscle and liver were all below 1.0. When combined with the average Canadian daily background exposure of $0.62 \mathrm{pg} / \mathrm{kg}$ bw/day, HQ values were still below 1.0 .

The key difference between the Alberta Health study and the current study is the species studied. Among the differences between species, deer and moose have different home ranges. The winter home range of deer is up to $4.5 \mathrm{~km}^{2}$ (Burris, 2005), while the average annual home range of moose is $202 \pm 59 \mathrm{~km}^{2}$ (Stenhouse et al., 1995). Therefore, a moose harvested in closer proximity to the ASWTC is less likely to have spent as much time in the contaminated zone and as such contaminants are unlikely to be accumulated to a similar extent. The calculation of benchmark consumption quantities showed how large the margin of safety was for total TEQ in moose meat from traditional harvest locations.

In order to determine whether or not moose harvested close to the ASWTC had higher TEQ values than moose harvested close to Kinuso (Figure 1), a $t$-test was performed. The mean TEQ of moose harvested closer to the ASWTC $(n=5)$ was compared with the mean TEQ from moose harvested near Kinuso $(n=9)$, locations approximately $60 \mathrm{~km}$ apart. Moose harvested near the ASWTC were approximately $15 \mathrm{~km}$ north of the facility, while moose harvested near Kinuso were approximately $60 \mathrm{~km}$ away from the ASWTC. A two-tailed $t$-test $(\alpha=0.05)$ showed no statistical differences for muscle $(p=0.8)$, kidney $(p=0.7)$, or liver $(p=0.5)$ indicating that moose harvested from areas closer to the ASWTC did not have statistically different PCB and $\mathrm{PCDD} / \mathrm{F}$ concentrations from moose harvested closer to Kinuso. One moose sample was harvested approximately $250 \mathrm{~km}$ away from the ASWTC to serve as a background sample. This sample showed no differences from the other moose samples in COPC concentrations or congener profiles.

Additional $t$-tests $(\alpha=0.05)$ were performed in order to determine whether or not there were any differences between concentrations in tissues from males and females and between adults and juveniles. Typically, adult males would be expected to have higher concentrations of TEQ than adult females due to the elimination of the lipophilic PCBs and PCDD/Fs in the milk fat during lactation (Suutari et al., 2012). Due to the bioaccumulative nature of the constituents, adults also would be expected to have higher TEQ concentrations than juveniles, simply because they have had longer to feed and accumulate PCBs and PCDD/Fs into their bodies. For all tissue types, there were no statistically significant differences for PCB/PCDD/F TEQ levels between males and females, or juveniles and adults. These results are in accordance with the deer tissues analyzed by Alberta Health (Alberta Health, 2013). 


\section{CONCLUSIONS}

The results of the study showed that organochlorine concentrations in the moose tissues from the SRFN were low. Concentrations of PCBs and PCDD/Fs in the moose tissues measured in the study were lower than historical results, and orders of magnitude lower than levels that would cause a concern at reported yearly consumption rates. With respect to PCBs and $\mathrm{PCDD} / \mathrm{Fs}$, consumption of moose tissue is safe in quantities in excess of the quantities documented by surrounding First Nations communities. The consumption of country foods poses no greater risk than foods from a grocery store.

When a spatial assessment of the moose tissue concentrations was completed there were no differences between tissue concentrations of $\mathrm{PCBs}$ or $\mathrm{PCDD} / \mathrm{Fs}$ in the moose harvested from the Swan Hills area or those from near the town of Kinuso, AB. A moose harvested approximately $250 \mathrm{~km}$ away from the ASWTC had concentrations within the ranges of all of those measured in the study.

Although the measured concentrations in the collected moose tissue samples are associated with low levels of environmental risk, this may not alleviate all of the concerns of the local hunters and harvesters with respect to traditional food quality due to continued concerns regarding animal home ranges. Many community members continue to be concerned about the quality of moose meat harvested in their traditional lands, leading to altered hunting patterns and the burden of needing to harvest moose further away from the facility. None of the samples collected for this study were in the immediate vicinity of the ASWTC. This suggests the negative impact a generation of food advisories has perhaps had on SRFN's harvesting practices. For this reason, further efforts to rebuild the confidence of local First Nations in game meat harvested in the vicinity of the ASWTC will be required.

The completion of this study and its results should provide assurances to the SRFN members that moose continues to be a healthy food option and that its consumption can continue at the reported quantities. However, it is uncertain if the impacts caused by the generation of food advisories can be overcome. Despite numerous historical studies conducted to determine if the area

\section{REFERENCES}

Alberta Health (2013). Swan Hills Treatment Center - Long-Term Follow-up Human Health Risk Assessment Program. Edmonton, AB: Government of Alberta.

ATSDR (1998). Toxicological Profile for Chlorinated Dibenzo-p-Dioxins. Atlanta, GA: Agency for Toxic Substances and Disease Registry, US Department of Health and Human Services, Public Health Service.

BC MOE (1995). Contaminated Site Statistical Application Guidance Document No. 5. Nonparametric Methods. A Guide for Data Analysts and Interpreters on Statistical Methods That Do Not Require a Distribution model. British Columbia Ministry of the Environment. Available online at: http://www2. gov.bc.ca/assets/gov/environment/air-land-water/site-remediation/docs/ guidance-documents/gd05.pdf

Burris, B. (2005). Seasonal Movements of White-Tailed Deer in Eastern South Dakota and Southwestern Minnesota Relative to Traditional Ranges and Management Unit Boundaries. M.Sc. thesis, Brookings, SD. is safe for traditional harvesting activities and uses, many Swan River members are not willing to return to the area for harvesting. SRFN members believe that a collared moose program would help eliminate uncertainty regarding home ranges and animal travel distances; this has not yet been undertaken.

\section{ETHICS STATEMENT}

This study was completed under the Health Canada Research Ethics Board Approval Number 2014-007.

\section{AUTHOR CONTRIBUTIONS}

$\mathrm{CM}$ and $\mathrm{AD}$ conceived of the study (based on requests from the SRFN) and participated in its design and coordination and helped to draft the manuscript. LK helped to draft the manuscript and conducted statistical and mathematical calculations. DS participated in the study design and coordinated its implementation with the First Nations community. CO and BK provided insight into data interpretation and critically reviewed the manuscript. BK also edited the original report. All authors read and approved the final manuscript.

\section{FUNDING}

Funding for this study was provided by the Government of Canada First Nations Environmental Contaminants Program. LK's position at Intrinsik is partially funded by the Natural Sciences and Engineering Research Council of Canada's (NSERC) Industrial R\&D Fellowship grant number 6037-2014-468358.

\section{ACKNOWLEDGMENTS}

The members of the Swan River First Nation collected all of the moose samples as part of the regular food harvesting of the Nation and then generously shared to allow for use in the study. Thanks are given to the Nation for retaining us to assist them in answering their research questions. Thank you to Andrew Thomason from Intrinsik for creating the map figure.

Chan, L., Receveur, O., Batal, M., David, W., Schwartz, H., Ing, A., et al. (2014). First Nations Food, Nutrition and Environment Study (FNFNES): Results from Ontario (2011/2014). Ottawa, ON: University of Ottawa.

Chan, L., Receveur, O., Batal, M., David, W., Schwartz, H., Ing, A., et al. (2016). First Nations Food, Nutrition and Environment Study (FNFNES): Results from Alberta 2013. Ottawa, ON: University of Ottawa.

Chan, L., Receveur, O., Sharp, D., Schwartz, H., Ing, A., Fediuk, K. et al. (2011). First Nations Food, Nutrition and Environment Study (FNFNES): Results from British Columbia (2008/2009). Prince George, BC: University of Northern British Columbia.

Chan, L., Receveur, O., Sharp, D., Schwartz, H., Ing, A., Fediuk, K., et al. (2012). First Nations Food, Nutrition and Environment Study (FNFNES): Results from Manitoba (2010). Prince George, BC: University of Northern British Columbia.

Cleverly, D., Schaum, J., Schweer, G., Becker, J., and Winters, D. (1997). "The congener profiles of anthropogenic sources of chlorinated dibenzo-pdioxins and chlorinated dibenzofurans in the United States," in Presentation 
at Dioxin '97, the 17th International Symposium on Chlorinated Dioxins and Related Compounds. Organohalogen Compounds, Vol. 32, 430-435. (Indianapolis, IN).

Dennis, J. (2008). The Traditional Environmental Monitoring and Risk Communication Project Final Report. Submitted to Health Canada.

Dennis, J. (2014). Traditional Environmental Monitoring Risk Communication Program (TEMRCP) TEMRCP Annual Report 2013.

Dersch, A. (2011). Past, Present, and Future Land Use of Swan River First Nation. Ph.D. thesis, Calgary, AB.

Health Canada (1995). Investigating Human Exposure to Contaminants in the Environment: A Handbook of Exposure Calculations, Vol. 1-3. Ottawa, ON: Government of Canada.

Health Canada (2005). It's Your Health: Dioxins and Furans. Original: November 2001; Updated: September 2005. Ottawa, ON: Government of Canada.

Health Canada (2010). Federal Contaminated Risk Assessment in Canada, Part II: Health Canada Toxicological Reference Values (TRVs) and Chemical-Specific Factors, Version 2.0. Ottawa, ON.

Health Canada (2012). Federal Contaminated Site Risk Assessment in Canada. Part I: Guidance on Human Health Preliminary Quantitative Risk Assessment, Version 2.0. Ottawa, ON: Government of Canada.

Health Canada (2016). Concentration of Contaminants \& Other Chemicals in Food Composites. Total Diet Study Results. [Online]. Available online at: http://www.hc-sc.gc.ca/fn-an/surveill/total-diet/concentration/index-eng.php (Accessed July 21, 2016).

Hutzinger, O., Choudhry, C. G., Chittim, B., and Johnston, L. E. (1985). Formation of polychlorinated dibenzofurand and dioxins during combustion, electrical equipment fires and PCB incineration. Environ. Health Perspect. 60, 3-9. doi: 10.1289/ehp.85603

McAuley, C., and Knopper, L. D. (2011). Impacts of traditional food consumption advisories: compliance, changes in diet and loss of confidence in traditional foods. Environ. Health. 10:55. doi: 10.1186/1476069X-10-55

Meyer, C., Black, R., Tolhurst, K., McCaw, L., Cook, G., Symons, R., et al. (2007). Emission of dioxins from bush fires in Australia. Organohalogen Compounds 69, 307-310. Available online at: http://www.dioxin20xx.org/pdfs/2007 07-383.pdf

SRFN (2012). Assessment of the Levels of PCBs, PCDDs, and PCDFs in Snow in the Vicinity of the Swan Hills Waste Treatment Centre in the Traditional Territory of the Swan River and Driftpile First Nations. Swan River, AB: Swan River First Nation.

SENA (2016). Swan Hills Treatment Centre. [Online]. Available online at: http://www.senawasteservices.com/SHTC.html
Stenhouse, G., Latour, P., Kutny, L., MacLean, N. and Glover, G. (1995). Productivity, survival, and movements of female moose in a low-density population, northwest territories, Canada. Arctic 48, 57-62. doi: 10.14430/ $\operatorname{arctic} 1224$

Suutari, A., Hallikainen, A., Ruokojarvi, P., Kiviranta, H., Nieminen, M., Laaksonen, S. (2012). Persistent organic pollutants in Finnish reindeer (Rangifer tarandus tarandus L.) and moose (Alces alces). Acta Vet. Scand. 54(Suppl. 1):S11. doi: 10.1186/1751-0147-54-S1-S11

US EPA (1989). Methods for Evaluating the Attainment of Cleanup Standards, Vol. 1, Soils and Solid Media. Washington, DC: United States Environmental Protection Agency.

US EPA (1991). Guidance for Risk Assessment. Washington, DC: Risk Assessment Council, United States Environmental Protection Agency.

US EPA (1996). Soil Screening guidance: User's Guide. Official Solid Waste and Emergency Response, 2nd Edn. Publication 9355.4-23. Washington, DC: United States Environmental Protection Agency.

US EPA (2002). Guidance for Comparing Background and Chemical Concentrations in Soil for CERCLA Sites. EPA 540-R-01-003-OSWER 9285. 7-41. Washington, DC: United States Environmental Protection Agency.

US EPA (2013). ProUCL Version 5.0.00. [Online]. Available online at https://www.epa.gov/land-research/proucl-software

Van den Berg, M., Birnbaum, L. S., Denison, M., De Vito, M., Farland, W., Feeley, M., et al. (2006). The 2005 World Health Organization reevaluation of human and mammalian toxic equivalency factors for dioxins and dioxin-like compounds. Toxicol. Sci. 93, 223-241. doi: 10.1093/toxsci/ kfl055

Van Oostdam, J., Donaldson, S., Feeley, M., Arnold, D., Ayotte, P., Bondy, G., et al. (2005). Human health implications of environmental contaminants in Arctic Canada: a review. Sci. Total Environ. 351-352, 165-246. doi: 10.1016/j.scitotenv.2005.03.034

Conflict of Interest Statement: The authors declare that the research was conducted in the absence of any commercial or financial relationships that could be construed as a potential conflict of interest.

Copyright (C) 2016 McAuley, Dersch, Kates, Sowan, Koppe and Ollson. This is an open-access article distributed under the terms of the Creative Commons Attribution License (CC BY). The use, distribution or reproduction in other forums is permitted, provided the original author(s) or licensor are credited and that the original publication in this journal is cited, in accordance with accepted academic practice. No use, distribution or reproduction is permitted which does not comply with these terms. 